\title{
Comprehensive approach to photonics education for technicians, engineers, and scientists in 4+2+2 programs
}

Leno Pedrotti, Nicholas Massa, Eric Soulsby, John Enderle, Chandrasekhar Roychoudhuri

Leno S. Pedrotti, Nicholas J. Massa, Eric P. Soulsby, John Enderle, Chandrasekhar Roychoudhuri, "Comprehensive approach to photonics education for technicians, engineers, and scientists in 4+2+2 programs," Proc. SPIE 2525, 1995 International Conference on Education in Optics, (13 October 1995); doi: 10.1117/12.224033

Event: SPIE's 1995 International Symposium on Optical Science, Engineering, and Instrumentation, 1995, San Diego, CA, United States 


\title{
Comprehensive approach to photonics education for technicians, engineers and scientists in $4+2+2$ programs
}

\author{
Leno S. Pedrotti \\ Center for Occupational Research and Development \\ Waco, Texas 76710 \\ Nicholas Massa \\ Springfield Technical Community College \\ Springfield, Massachusetts 01105 \\ Eric P. Soulsby \\ John Enderle \\ Chandra S. Roychoudhuri \\ University of Connecticut \\ Storrs, Connecticut 06269
}

\begin{abstract}
This paper outlines a curricular plan for the education of photonics technicians, engineers, and scientists in $4+2+2$ programs. These programs begin at the 9 th grade in high school and end either at the 14th grade ( $4+2$ programs) with an associate of applied science degree, or at the 16th grade $(4+2+2$ programs) with a bachelor of science degree. Beginning with comprehensive lists of appropriate tasks for photonics technicians - as identified by photonics-related industriesextrapolation is made to specific courses, sequences of courses, and suggested programs. The foundations are set in place first in four-year high school programs, with emphasis on basics in mathematics, science, communications and introductory technology courses. Then postsecondary level programs, through the 13th and 14th year, present the breadth and depth of skills required for the development of entry-level photonics technicians. Finally, articulated programs from two-year colleges on to four-year colleges are outlined for those who opt to continue on for a bachelor of science degree and who plan to enter the photonics workforce with concentration in electrical engineering and/or optics.
\end{abstract}

Keywords: photonics, industry-generated task lists, education, workforce preparation, $4+2+2$ education plans

\section{BACKGROUND}

Photonics is an emerging, 21st century technology involved directly with the generation, manipulation, transport, detection, and use of electromagnetic energy and information. It stands today as the logical successor to what many of us referred to formerly as laser electro-optics. It encompasses generally the traditional fields of optics, lasers, and electronics, and plays a key role as a major technology in the diverse industries of medicine, transportation, manufacturing, communication, public safety, national defense, aerospace, entertainment, imaging, displays, and environmental monitoring.

Because of its critical role in support of so many major industries, there is an increasing need in the workforce for qualified photonics technicians, engineers, and scientists, both now and for the foreseeable future. Surveys of the photonics-connected industries bear this out, indicating roughly a doubling from the 345,000 photonics technicians employed today to the approximately 743,000 needed by the year $2000^{1}$. If the United States is to remain competitive in the broad arena of photonics-related industries, it must be capable of producing a quality photonics workforce, year after year. 
With photonics clearly established as an important expanding technology in support of the business sector, and with clear signals for increased numbers of skilled workers, we need to concern ourselves with such questions as:

- Which skills should photonics technicians have?

- How do we translate knowledge of skills to specific educational curricula?

- How should the education community organize itself to deliver the photonics workforce we need?

In the balance of this paper we concern ourselves with answers to these questions. We outline a general process that takes us from raw data on photonics tasks in the workplace to photonics-related curricula in the school house. We offer prototype curriculum programs, with suggestions for courses and sequences, at the high school and postsecondary levels. We suggest a linear integration of educational institutions in a so-called $4+2+2$ plan, coordinating efforts between four-year high schools, two-year postsecondary schools, and four-year colleges and universities. The essential features of a $4+2+2$ plan are shown in Figure 1. There we see the linkage between the educational institutions, the various exit points, and the levels of proficiency achieved at these points.

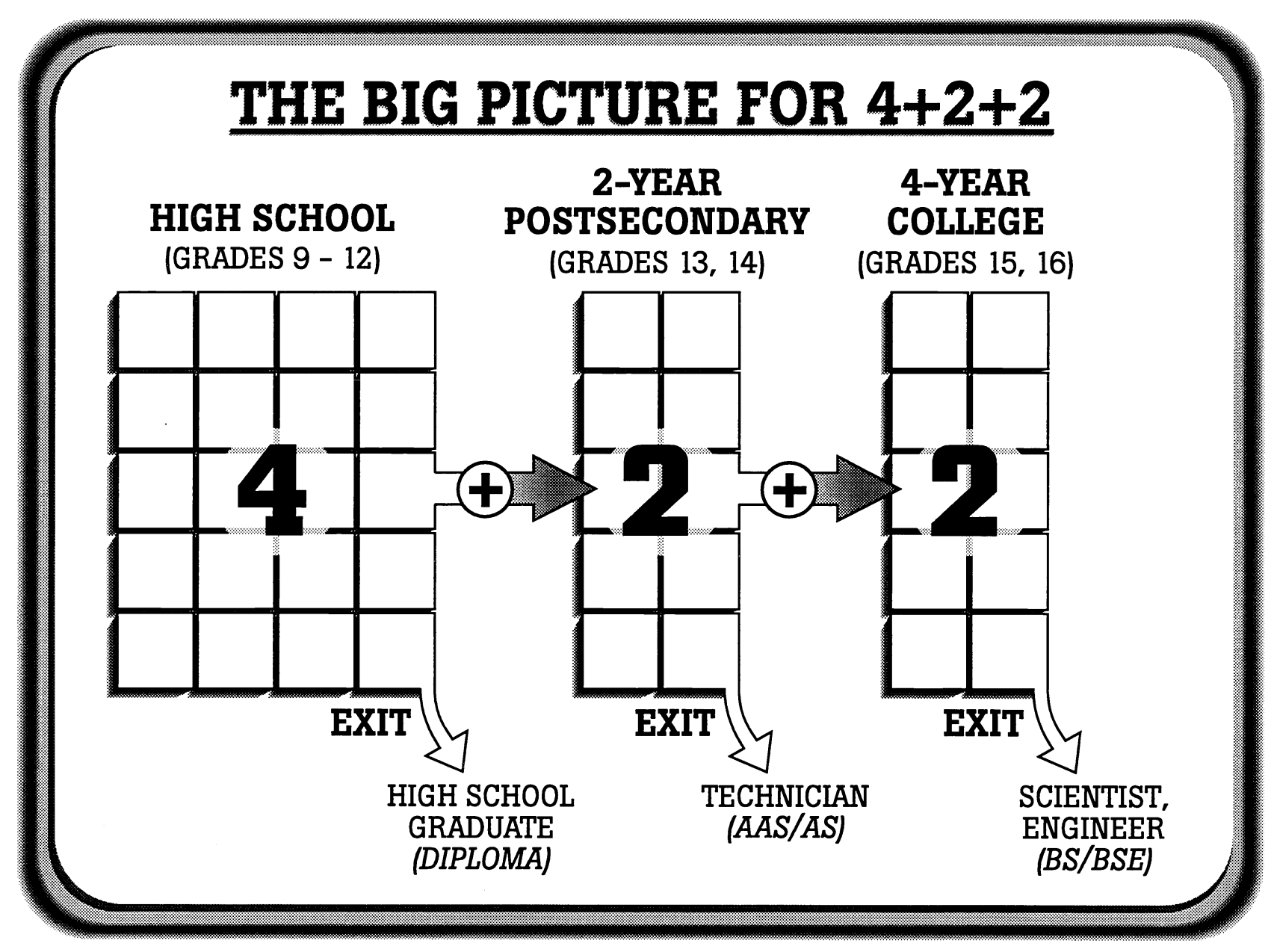

Figure 1. A general $4+2+2$ plan for preparing a photonics workforce

Several points should be made relative to Figure 1 and a $4+2+2$ plan.

- Some students in a $4+2+2$ pipeline will exit after high school graduation. While "early" exit is not the objective of the education plan, we must accept that it will happen. Those that do leave at this point will 
not contribute directly to the photonics workforce we seek. But, if we plan their four-year high school programs carefully, with good foundations in mathematics, science, communications, computers, and hands-on laboratory skills, we will have prepared them with the sound entry-level job skills required by many industries - and the background necessary to reenter formal education at a later date.

- The main thrust of the $4+2+2$ plan is to prepare photonics technicians, with an associate degree, through the 14th grade level-the so-called $4+2$ plan. This part of the education plan may occur at the two-year institutions - community colleges or technical institutes-or in associate degree programs that are embedded within four-year colleges.

- For those who wish to move from the technician level to the scientist/engineer level in the full $4+2+2$ plan, the final two years are completed at a four-year college or university, with a bachelor's degree at the exit point. Clearly, careful articulation between education at the 13/14-year level and the 15/16-year level must occur.

\section{FROM WORK-BASED TASKS TO CURRICULA}

The photonics-related industries, vast in number, are surely those which must identify the tasks and indicate the levels of performance expected of the photonics technicians they employ. This is a challenging, but doable job. With support from the U.S. Department of Education, the Center for Occupational Research and Development (CORD) ${ }^{2}$ has begun the process of working with industries to catalog the immense list of diverse tasks and skills required, and to indicate the level at which they are to be performed. In a reference alluded to earlier, many of the tasks have been identified by industry and described in compact statements such as the following:

- Operate, maintain, align and troubleshoot $N d: Y A G$ lasers

- Clean, maintain, align, mount, install, and operate spectroscopic instruments in laser-optical systems

- Troubleshoot, repair, maintain, and use electronic power supplies used in laser systems

- Install, align, clean, maintain and operate A-O modulators and Q-switches in laser systems

Even in this small sample of tasks, it is clear that the first task requires detailed knowledge of lasers, the second of spectroscopic instrumentation and optics, the third of electronic power supplies and electronics, and the fourth of laser support equipment and laboratory technique. The point here is that with tasks identified, educators can begin to identify the knowledge and laboratory components, the courses, the sequences, and then assemble these block by block to form the required curriculum. Since the sample tasks referred to above are at the level of on-the-job performance, they are considered to be "exit" tasks for the photonics technician. As such, the ability to perform these tasks must be guaranteed by the educational process, beginning at the 9th grade of high school and extending through the 14th grade associate degree level. Higher-level tasks will be learned with experience on the job.

The four sample tasks listed above are clearly photonics-specific. They indicate little of the foundation skills in science, mathematics and communication which also must be part of the technicians complete tool kit. Educators, therefore, through analysis of the comprehensive task lists, must glean the necessary foundation skills and make them an integral part of the curricular program. Several samples of required knowledge components in mathematics and science are given below:

- Samples of useful mathematics skills learned in applied mathematics courses:

- Learn how to use scientific calculators, estimate and round numbers

- Learn about perimeters and areas of rectangles, triangles, parallelograms, trapezoids and circles

- Learn about surface areas and volumes of boxes, cones, cylinders, and spheres

- Use ratio and proportion to make and read scale drawings, and make generalizations

- Learn about precision, accuracy and tolerance in measurement

- Learn about roots and powers

- Solve linear and nonlinear equations for a specified variable

- Learn how to draw and interpret graphs

- Use metal tapes, vernier calipers, micrometer calipers, for example, to measure distance 
- Samples of useful science skills learned in applied physics courses:

- Learn about relationships between distance, speed, acceleration and time in linear and angular motion

- Learn about pressure and flow rates in fluid systems

- Measure energy, power and efficiency of mechanical, fluid, electrical and thermal devices

- Learn how to measure flow rate, pressure, temperature, force, voltage, current and resistance with appropriate instruments

- Learn how to use a dual-trace oscilloscope to troubleshoot circuits and to measure voltage and frequency

- Learn how to assemble equipment from schematic or pictorial diagrams

- Use appropriate transducers to measure mechanical, fluid, electrical and thermal signals

- Learn how to assemble lenses, mirrors, prisms, sources and detectors in optical systems

Beginning, then, with a careful analysis of the tasks/skills identified by the photonics-related industries, the generalization to course content and laboratory practice leads to course identification and program definition. Such an analysis, although still incomplete, led to the following sets of courses in $4+2$ programs for photonics technicians.

- Foundation Courses

Applied Mathematics - algebra, geometry, trigonometry, statistics, QAVQC

Applied Science -- physics, chemistry, biology

Communications - oral/written presentations in the workplace; teamwork

- Photonics Core Courses

Introduction to Photonics

Optical Principles

Support and Positioning Equipment

Optical Components

Electronics for Photonics Applications

Photonic Controllers

Imaging and Display

Computer Interfaces

Detection and Measurement

Photonics Safety and Worksite Practices

Laser Sources

Fiber Optics

Vacuum Technology

- Specialty Courses

Optical Communication Systems

Spectroscopic Systems

Materials Processing Systems

Holography and HNDT Systems

The flow process, from an industry-validated list of tasks and skills to a $4+2$ curriculum, is shown in Figure 2 . Beginning with the task lists, there are generally two levels of sorting that occur. This sorting begins with a general listing of the major course areas-under the headings of foundation courses, technical core courses, and specialty courses-and progresses to a more detailed, course-by-course listing of the new and existing courses required for a $4+2$ photonics curriculum. The courses are then arranged sequentially in discipline strands, culminating in a six-year curricular plan for photonics technicians. 


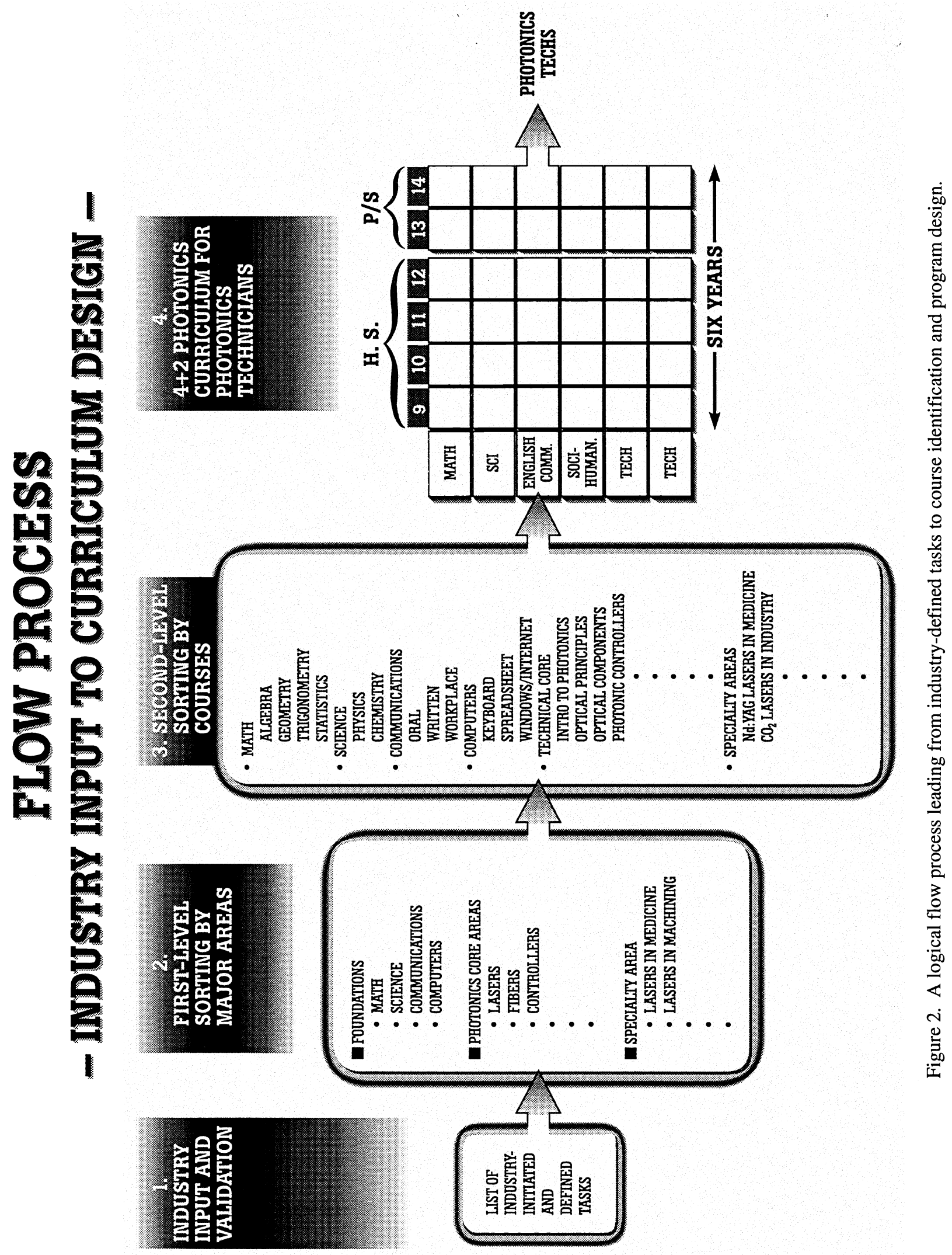




\section{THE HIGH SCHOOL PART — LAYING THE FOUNDATION}

The first block in the $4+2+2$ plan - the four years in high school-provides us with an opportunity to set in place important foundation courses in mathematics, science, English, humanities, communications, computers, work ethics, and laboratoryassociated hand skills. It can be designed effectively once the big picture (Figure 1) is understood in its entirety, and once the flow process (Figure 2) has identified the courses needed to guarantee the exit skills desired at the 14th year or 16th year exit points.

It is important that four-year high school programs be designed with the full knowledge and agreement of the faculty and administration of the 13/14 year school, since the latter is to build on the foundation laid in grades 9-12, and is to complete the education for the photonics technician at the 14th year. This critical coordination process requires that barriers between high schools and two-year postsecondary schools be lowered, and that effective dialog be established between mathematics teachers, science teachers, and technology teachers at both institutions. When this happens, one can build a seamless sixyear program, avoid duplication of courses, and develop those required courses that fit together and work together to prepare the highest-level technician possible in a six-year time frame.

Figure 3 indicates a possible outline for the foundation courses and introductory technology courses to be completed in high school. (Note that we have not listed all courses generally required for a high school diploma.)

\section{THE HIGH SCHOOL PART OF 4+2+2}

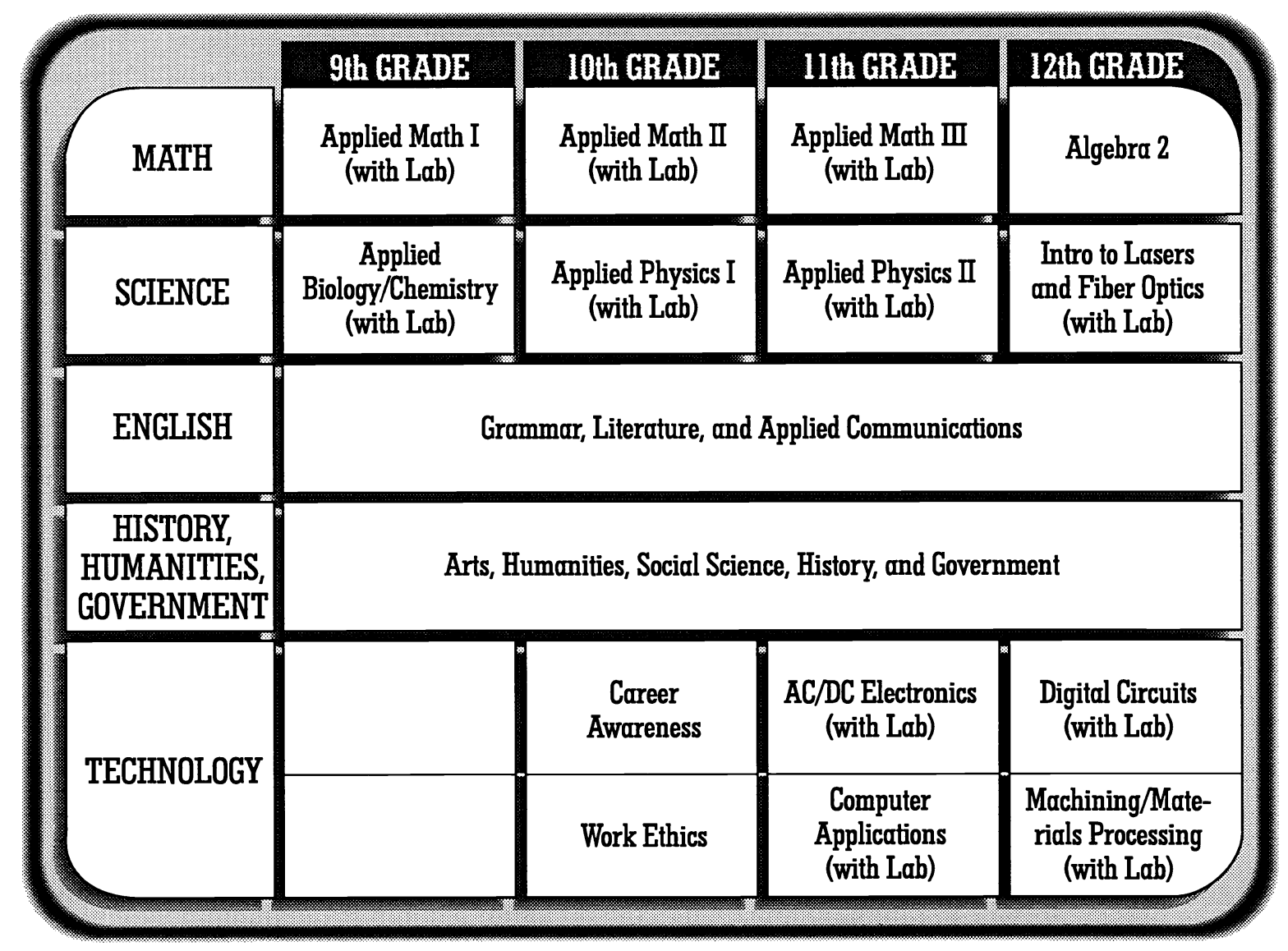

Figure 3. Building the foundation at the high school level 
It is imperative that the mathematics and science courses be taught contextually, that they relate to technology, and that they connect with practices in the real world. All of this is to emphasize that critical foundation courses in math and science be applied in nature, be relevant and practical, and make sense to those who are not necessarily the abstract thinkers we find in the top $20 \%$ of our high school populations. The courses labeled applied mathematics, applied biology/chemistry, and applied physics have been developed (by CORD) to meet the conditions specified above. (To date, some 2,330,000 high school students have enrolled in such courses since 1985.) Note especially that the development of good laboratory measurement skills is important at the high school level. Thus, in Figure 3, we show eight science and technology courses, each associated with a substantial laboratory component. Note also that the three applied mathematics courses-which cover the essentials of algebra, geometry, some trigonometry, probability, statistics and quality assurance/quality control—contain hands-on laboratory practice. In these mathematics laboratories, students measure with metal tapes, cloth tapes, metersticks, vernier calipers, micrometer calipers, stopwatches, line levels, plumb bobs, carpenter squares, spring scales, and thermometers. In these contextually-designed laboratories, students collect data, then use the appropriate mathematics to solve the relevant problems posed in the laboratories. This is the heart of contextual learning.

The technology courses shown in Figure 3 are broad in nature, with a heavy emphasis on electronics and mechanical devices. These are considered to be important foundation courses for those heading for careers in photonics-or elsewhere. The technology courses, in the junior/senior year, are taught by instructors who have full knowledge (ideally) of the mathematics and science concepts developed in the earlier years. Thus, they can present the technology on a good foundation of math and science. In the same spirit, the mathematics and science teachers who teach the foundation courses know (ideally) what will be required of their subject matter in the technology courses, thereby enabling them to teach the foundation skills more effectively. The course listed as Introduction to Lasers and Fiber Optics, in the senior year, builds on the math and science competencies developed earlier, and is intended to provide the motivation for students to continue on, after high school, for more schooling in photonics at the postsecondary level.

\section{THE 13/14 YEARS — PREPARING THE TECHNICIAN AT THE AS/AAS LEVEL}

The 13/14 years of postsecondary schooling build on the foundations developed at the high school level and provide the learner with the depth and specialization needed to graduate as a photonics technician at the associate degree level. This phase of the $4+2+2$ education takes place generally at two-year postsecondary institutions, such as community colleges and technical institutes, but may, in fact, occur at four-year institutions of higher learning, wherein we find that two-year associate degree programs are available.

Again, it is important to emphasize the seamless nature of the first six years of the $4+2+2$ plan. The ideal program consists of a carefully crafted curriculum of four years of foundation courses at the 9-12 level, meshing smoothly and logically with the two follow-on years at the 13-14 level. The 4+2 plan works best when the "4" and the " 2 " are designed simultaneously, in a six-year package, as suggested in Figure 4.

It is apparent that the fourteen or so technical courses in the 13/14 years provide the depth and breadth required for the preparation of the photonics technician, with the exit skills identified by industry. These courses, as indicated earlier, are identified as a result of the analysis of the task lists obtained from photonics-related industries, as outlined in Figure 2 . If the high school foundations have been set in place, a pedagogically sound progression through the 13/14 years is assured. In Figure 4, note that the emphasis has been on listing-by title- the foundation and technical core courses which apply to the education of photonics technicians. It is readily acknowledged that other courses are needed to meet local and state requirements for a high school diploma and a two-year associate degree. There should be enough room in the above $4+2$ plan to accommodate these other requirements.

The authors feel that a six-year curriculum plan, such as the one suggested in Figure 4, should be developed in a fully coordinated, cooperative effort between geographically-related high schools and postsecondary colleges, and placed in the hands of all high school counselors. With this information available at the beginning high school level, counselors can advise entering students effectively, and outline successful career paths that lead to the photonics workforce required in our industries. 


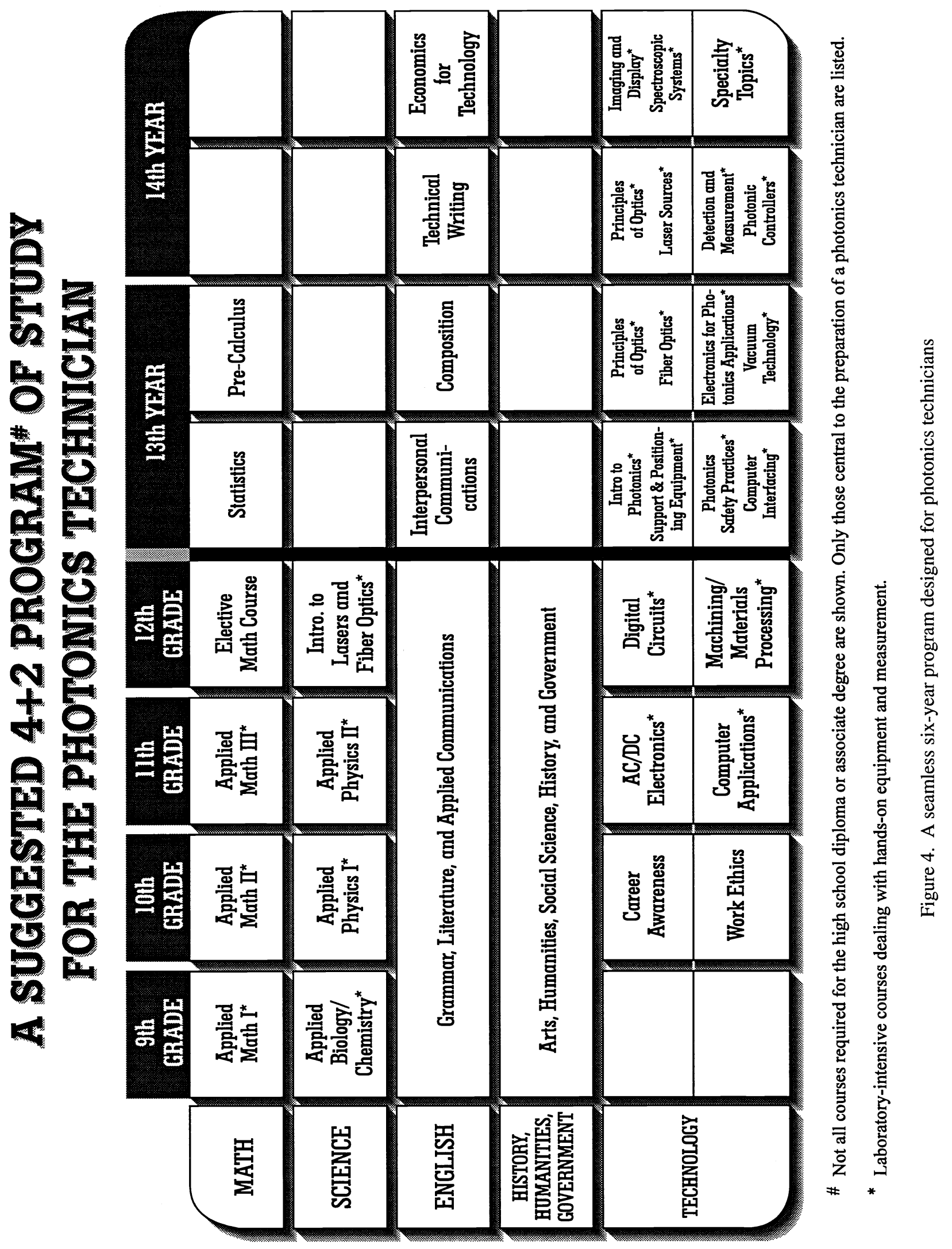


As mentioned earlier, for those students progressing in a 4+2 plan, headed toward an associate degree with preparation as a technician, the option is there for them, in a $4+2+2$ plan, to complete the 15 th and 16 th years (the junior/senior years at a four-year institution of higher learning) and to graduate as a photonics engineer or scientist. (At this point, a small number of students are exercising this option.) In this spirit, then, effective coordination and articulation should occur between the two-year programs at the 13/14-year institutions and 15/16-year programs at specific four-year colleges and universities, just as was required between the high school and the 13/14-year school. We consider this challenge in the final section of this paper.

\section{THE 15/16 YEARS - HEADING FOR A BACHELOR OF SCIENCE LEVEL}

In designing a seamless transition from the two-year to the four-year institution, it should be noted that because of the limited number of institutions presently offering the BS degree in Photonics, there are generally two options available: (1) the BS degree in Engineering Technology (BSET), and (2) the BS degree in Electrical Engineering (BSEE). Other options such as Optical Engineering and Applied Physics may also be considered. However, because of the heavy emphasis on electronics and instrumentation in a photonics curriculum, the transition to either of these two options may not be a natural one.

\subsection{The BSET option}

The BS degree in Engineering Technology is fairly well established and is available at many four-year institutions across the country. The typical BSET program tends to be less rigorous in the mathematics and theoretical aspects of engineering than the traditional BSEE program, but emphasizes a more practical "hands-on" type engineering approach. Graduates of such programs find employment in all aspects of engineering including research and development, but most often in the areas of project engineering, product development, applications engineering, and field service. BSET graduates can continue on to graduate school, but may require several additional undergraduate courses to complete the prerequisite requirements for certain graduate-level engineering courses.

Many two-year institutions with associate degree programs in engineering technology already have well established articulation agreements $(2+2)$ with four-year institutions, and have been engaged in relatively seamless transitions for many years. In some cases, the four-year institution itself may offer both the associate degree and the BS degree, making for an ideal situation.

For students transferring from a two-year to a four-year institution, the third and fourth years are spent largely making up the math and science courses typically taken during the first two years by students who attend the four-year institution from the start. Many of the technical courses taken at the two-year institution may be used as upper level technical electives at the four-year institution. Typical transfer agreements between two-year and four-year colleges are shown in Figure 5. In any event, the transition from the two-year to the four-year institution in the BSET program can be made smoothly, providing the curricula is designed with articulation in mind from the start.

In the field of photonics, because of the relatively few (two or three) four-year institutions nationwide that offer the BS degree in Photonics, students completing their associate degree in Laser Electro-Optics Technology (LEOT) typically continue their education by pursuing the BS degree in Electronic Engineering Technology (BSEET). Although not a perfect marriage, the transition can be fairly smooth because of the strong similarities in subject matter. Students graduating with the dual LEOT/BSEET degree tend to have somewhat of an advantage over the traditional BSEET graduate because of the specialized training in photonics at the two-year level, which sets them apart and gives them an edge in the job market. As the photonics field continues to emerge and more and more institutions begin to offer BS degrees in Photonics, the number of students taking advantage of the $2+2$ opportunity for career advancement should increase dramatically.

\subsection{The BSEE option}

The second alternative available for students who wish to continue their education to the BS-degree level is the traditional BSEE program. To date, most of the scientists and engineers currently working in the field of photonics are graduates of 


\section{Engineering \& Science Transfer Courses}

(72-73 credits)

Semester I

\begin{tabular}{|c|l|c|}
\hline $\begin{array}{c}\text { Course } \\
\text { Number }\end{array}$ & \multicolumn{1}{|c|}{ Course Title } & Credits \\
\hline MM 155 & Calculus I & 4 \\
\hline MC 103 & General Chemistry I & 4 \\
\hline ME 203 & Computer Applications in Engineering & 4 \\
& & \\
\hline LE 100 & English Composition I & 3 \\
\hline NE 100 & Principles of Economics & 3 \\
\hline
\end{tabular}

Semester II

\begin{tabular}{|c|l|c|}
\hline $\begin{array}{c}\text { Course } \\
\text { Number }\end{array}$ & \multicolumn{1}{|c|}{ Course Title } & Credits \\
\hline MM 255 & Calculus II & 4 \\
\hline MC 203 & General Chemistry II & 4 \\
\hline MP 132 & University Physics I & 4 \\
\hline ME 108 & Pascal & 4 \\
\hline LE 200 & English Composition II & 3 \\
\hline
\end{tabular}

Semester III

\begin{tabular}{|l|l|c|}
\hline $\begin{array}{c}\text { Course } \\
\text { Number }\end{array}$ & \multicolumn{1}{|c|}{ Course Title } & Credits \\
\hline MM 355 & Calculus III & 4 \\
\hline MP 232 & University Physics II & 4 \\
\hline ME 310 & Mechanics I (Statics) & 4 \\
\hline ME 320 & Circuit Analysis I & 3 \\
\hline ME 324 & Lab I & 1 \\
\hline & Hum./Social Science Electives & 3 \\
\hline
\end{tabular}

Semester IV

\begin{tabular}{|l|l|c|}
\hline $\begin{array}{c}\text { Course } \\
\text { Number }\end{array}$ & \multicolumn{1}{|c|}{ Course Title } & Credits \\
\hline MM 455 & Differential Equations & 4 \\
\hline ME 410 & Mechaniss II(Dynamics) & 3 \\
\hline & "Engineering Electives & $3-4$ \\
\hline & "Engineering Electives & 3 \\
\hline & History Elective & 3 \\
\hline
\end{tabular}

\section{Laser Electro-Optics Technology Transfer Courses}

( 21 credits)

\begin{tabular}{|l|l|c|}
\hline $\begin{array}{c}\text { Course } \\
\text { Number }\end{array}$ & \multicolumn{1}{|c|}{ Course Title } & Credits \\
\hline & & \\
\hline & & \\
\hline ET 111 & Intro to Computer Aided Engineering Technology & 3 \\
E 225 & Computer Applications & 2 \\
\hline LE 100 & English Composition I & 3 \\
\hline & & \\
\hline
\end{tabular}

\begin{tabular}{|c|c|c|}
\hline $\begin{array}{c}\text { Course } \\
\text { Number }\end{array}$ & \multicolumn{1}{|c|}{ Course Title } & Credits \\
\hline & & \\
\hline & & \\
\hline MP 120 & Technical Physics I & 4 \\
\hline & & \\
\hline LE 202 & Technical Report Writing & 3 \\
\hline
\end{tabular}

Figure 5. Typical transfer agreements for engineering/service courses and for technology courses between two-year and four-year colleges. 


\section{Third Year Sequence (including two summers)}

Summer I
\begin{tabular}{|c|c|c|}
\hline $\begin{array}{c}\text { Course } \\
\text { Number }\end{array}$ & Course Title & Credits \\
\hline MM 155 & Calculus I & 4 \\
\hline MM 255 & Calculus II & 4 \\
\hline
\end{tabular}

Semester V
\begin{tabular}{|l|l|c|}
\hline $\begin{array}{c}\text { Course } \\
\text { Number }\end{array}$ & \multicolumn{1}{|c|}{ Course Title } & Credits \\
\hline ME 310 & Mechanics I & 4 \\
\hline MP 232 & University Physics II & 4 \\
\hline MM 355 & Calculus III & 4 \\
\hline NE 100 & Principles of Economics & 3 \\
\hline ME 320 & Circuit Analysis I & 3 \\
\hline ME 324 & Lab I & 1 \\
\hline
\end{tabular}

\section{Semester VI}

\begin{tabular}{|c|l|c|}
\hline $\begin{array}{c}\text { Course } \\
\text { Number }\end{array}$ & \multicolumn{1}{|c|}{ Course Title } & Credits \\
\hline ME 410 & Mechanics II & 4 \\
\hline ME 108 & Pascal & 4 \\
\hline MM 455 & Differential Equations & 4 \\
\hline ME 420 & Circuit Analysis II & 3 \\
\hline ME 427 & Lab II & 1 \\
\hline & History Elective & 3 \\
\hline
\end{tabular}

Summer II
\begin{tabular}{|c|c|c|}
\hline $\begin{array}{c}\text { Course } \\
\text { Number }\end{array}$ & \multicolumn{1}{|c|}{ Course Title } & Credits \\
\hline MC 103 & General Chemistry I & 4 \\
\hline MC 203 & General Chemistry II & 4 \\
\hline
\end{tabular}

Figure 6. Typical sequence of courses required in a "third" year at the two-year college to prepare for a transfer from a two-year technology program to a four-year BS program. 
traditional electrical engineering programs. Many of the four-year institutions that offer the BSEE degree also offer a variety of photonics-related electives which, although typically not the major thrust of the program at the undergraduate level, can provide enough of a foundation in photonics for the graduating engineer to obtain employment in the field.

The transition from a two-year engineering technology program to a traditional four-year BSEE program is not as seamless as the BSET transition. Because of the more rigorous calculus-based nature of the typical BSEE curriculum, the best one can hope for is a " $2+1+2$ " program; two years in the engineering technology program, one year to make up the math, science, and engineering core course requirements (see Figure 6), and the final two years at the four-year institution, for a total of five years. Although an additional year is required, the benefits may be well worth the extra time spent for the following reasons.

- Many two-year institutions that offer formal AS degree programs in engineering and science transfer, in addition to the AS degree in engineering technology, are ideally suited for such a program. The student can spend three years at the two-year institution and then transfer to the four-year institution for the final two years. The benefits are the significant cost savings made possible by attending a two-year community college for three years.

- The student has three possible exit points:

- AS degree in Engineering Technology - The student has immediate employable skills and can enter the workforce after just two years.

- AS degree in Engineering Transfer - After completing one more year, the student is prepared for acceptance into most four-year engineering programs. He/she may continue onto the four-year program immediately, or enter the workforce and postpone the BS degree to a later date.

- BSEE degree - By completing the final two years, the student is prepared to enter the workforce as an electrical engineer or may continue on to graduate school.

- Because students transferring from a two-year technology-based program are trained extensively in "hands-on" applications, their level of understanding of the subject matter presented in the upper level, theory-based engineering courses is greatly enhanced. They have seen the "real world" applications of the subject being studied which helps to make complex concepts more understandable.

- Two-year engineering technology programs, which are typically offered at local community colleges, tend to attract students (both traditional and nontraditional) who are not yet prepared to enter four-year programs due to either academic, economic, or other factors. This, in fact, represents a large body of students who are capable of matriculating to a four-year institution and succeeding because of the confidence and motivation gained by successfully completing the two-year program.

In conclusion, we note that any seamless transition, whether $4+2,4+2+2$, or $4+2+1+2$ can be successful if all parties involved work together from the beginning to define a curriculum which minimizes the time requirement and maximizes the quality and transferability of courses. As far as photonics is concerned, as more BS degree programs in Photonics emerge, the ability of students enrolled in AS degree programs in photonics, laser/electrooptics, and related fields to further their education should improve dramatically.

\section{REFERENCES}

\footnotetext{
${ }^{1}$ Troy, Charles T. "Standards Issued for Photonics Technicians," Photonics Spectra, Laurin Publishing Co., Inc., April 1995, p 58.

2 CORD is a nonprofit, public service organization located in Waco, Texas. CORD helps educators in schools and industry address the technical education, training and retraining needs of the workforce.
} 